\title{
MicroRNA-216b regulated proliferation and invasion of non-small cell lung cancer by targeting SOX9
}

\author{
SIDA LIU ${ }^{1}$, HAN DONG $^{2}$, HUI DAI $^{3}$, DANWEI LIU ${ }^{4}$ and ZHIHAO WANG ${ }^{2}$ \\ ${ }^{1}$ Department of Thoracic Surgery, XinHua Hospital Affiliated to Shanghai Jiao Tong University School of Medicine, \\ Shanghai 200092; ${ }^{2}$ Department of Geriatrics, The First Hospital of Jilin University; ${ }^{3}$ Department of \\ Tumor and Blood Disease, The Affiliated Hospital to Changchun University of Chinese Medicine; \\ ${ }^{4}$ Department of Infections, People's Hospital of Jilin Province, Changchun, Jilin 130021, P.R. China
}

Received February 3, 2016; Accepted December 21, 2016

DOI: $10.3892 / \mathrm{ol} .2018 .8573$

\begin{abstract}
Micro (mi)RNAs are small, evolutionarily conserved and endogenous noncoding RNA molecules between 19 and 24 nucleotides in length. The potential roles of miRNAs in the carcinogenesis and progression of non-small cell lung cancer (NSCLC) have been studied previously. In the present study, it was revealed that miRNA-216b (miR-216b) expression was lower in NSCLC tissue and cell lines compared with that in adjacent healthy lung tissue samples and the normal bronchial epithelial 16HBE cell line, respectively. The ectopic expression of miR-216b inhibited the proliferation and invasion of NSCLC cells in vitro. SRY-Box 9 (SOX9) was identified as a direct target of miR-216b in NSCLC. In addition, SOX9 small interfering RNA was able to mimic the effects of miR-216b overexpression on cell proliferation and invasion in NSCLC. Therefore, the data reported in the present study demonstrate that miR-216b is an important tumor suppressor in NSCLC. These data may contribute to the understanding of the molecular mechanism underlying the carcinogenesis and progression of NSCLC, and provide novel therapies for patients with NSCLC.
\end{abstract}

\section{Introduction}

Lung cancer is the most prevalent type of cancer in the world, and the leading cause of cancer-associated mortality worldwide (1). In 2015, it was estimated that there would be 221,200 incident cases and 158,040 mortalities due to lung cancer in the United States (2). Histologically, lung cancer is classified into two major groups: Non-small cell lung cancer (NSCLC) and small cell lung cancer (SCLC) (3). NSCLC,

Correspondence to: Professor Zhihao Wang, Department of Geriatrics, The First Hospital of Jilin University, 71 XinMin Street, Changchun, Jilin 130021, P.R. China

E-mail: zhihaowang_fhjlu@163.com

Key words: non-small-cell lung cancer, microRNA-216b, proliferation, invasion, SRY-Box 9 which accounts for $\sim 80 \%$ of primary lung cancer, may be divided into four subtypes: Adenocarcinoma (ADC), squamous cell carcinoma (SCC), adenosquamous cell carcinoma and large cell carcinoma (LCC) (4). Typically, the carcinogenesis and progression of NSCLC is a multi-stage process, which is hypothesized to involve the deregulation of multiple genes that are critical for a number of cellular processes including cell cycle control, growth, apoptosis, migration and spreading (5-7). Previously, there have been improvements in the therapy for patients with NSCLC, including surgery, radiotherapy, chemotherapy and molecular targeted therapy; however, the prognosis for patients with NSCLC remains poor (8). Therefore, it is important to understand the molecular mechanisms underlying the tumorigenesis and development of NSCLC, and examine novel therapeutic treatments for patients with NSCLC.

Micro (mi)RNAs are small, evolutionarily conserved and endogenous noncoding RNA molecules between 19 and 24 nucleotides in length (9). They regulate gene expression through interaction with the $3^{\prime}$ untranslated regions (3'UTRs) of target mRNAs, resulting in the inhibition of the post-transcriptional translation or the degradation of the target mRNAs (10). At present, it is estimated that miRNAs may be responsible for regulating $>70 \%$ of the coding genes in the human genome (11). Emerging data have demonstrated that the abnormal expression of miRNAs contributes to a number of diverse biological and pathological processes in cancer cells, including in cell proliferation, cell cycle, differentiation, development, apoptosis, migration, invasion and metastasis (12-14). Previous studies have revealed that miRNAs are involved in the carcinogenesis and progression of several types of human cancer as either oncogenes or tumor suppressors, depending on the functions of their target mRNAs (15-17). The inactivation of oncogenic miRNAs, or restoration of tumor suppressing miRNAs, has demonstrated potential in providing therapeutic treatments for patients with cancer, and the strategies are undergoing clinical trials (18-22).

In the present study, the level of miRNA (miR)-216b expression in NSCLC tissues and cell lines was investigated. The effects of miR-216b overexpression on cellular proliferation and invasion in NSCLC were also evaluated. It was revealed that miR-216b was downregulated, and acted as a 
negative regulator of proliferation and invasion of NSCLC cells. It was also identified that the molecular mechanism of miR-216b inhibiting the proliferation and invasion of the NSCLC cells may be through targeting the SRY-Box 9 (SOX9) gene in NSCLC.

\section{Materials and methods}

Human tissue samples. The present study was approved by the Ethics Committee of the XinHua Hospital Affiliated to Shanghai Jiao Tong University School of Medicine (Shanghai, China). A total of 16 paired NSCLC tissues and adjacent non-tumor lung tissues were collected from patients with NSCLC who underwent surgery at the XinHua Hospital Affiliated to Shanghai Jiao Tong University School of Medicine (Shanghai, China). These samples were immediately snap-frozen in liquid nitrogen and stored at $-80^{\circ} \mathrm{C}$.

Cell culture. The NSCLC H23, H460, H520 and A549 cell lines, normal bronchial epithelial 16HBE cell line and HEK293T cell line were obtained from American type culture collection (Manassas, VA, USA) and cultured in Dulbecco's modified Eagle's medium containing $10 \%$ fetal bovine serum (FBS), $2 \mu \mathrm{M}$ glutamine, $100 \mathrm{IU} / \mathrm{ml}$ penicillin and $100 \mu \mathrm{g} / \mathrm{ml}$ streptomycin (all Gibco; Thermo Fisher Scientific, Inc., Waltham, $\mathrm{MA}, \mathrm{USA}$ ) at $37^{\circ} \mathrm{C}$ in $5 \% \mathrm{CO}_{2}$ cell incubator.

miRNA/small interfering (si)RNA transfection. The miR-216b mimics, negative control (NC), SOX9 siRNA and siRNA-NC were produced by Shanghai GenePharma Co., Ltd., (Shanghai, China). The NSCLC cells were seeded into 6-well plates at a density of $3 \times 10^{5}$ cells/well and transfected with miRNA/siRNA using Lipofectamine ${ }^{\circledR} 2000$ reagent (Invitrogen; Thermo Fisher Scientific, Inc.) following the protocol of the manufacturer.

$R N A$ isolation and reverse transcription quantitative polymerase chain reaction ( $R T-q P C R)$. Total RNA was extracted from tissue samples and cells using TRIzol reagent (Invitrogen; Thermo Fisher Scientific, Inc.) according to the manufacturer's protocol.

A total of $2 \mu \mathrm{l}$ DNase I (ABgene, Shanghai, China) without RNase was used to eliminate the remaining DNA genome. cDNA was synthesized from total RNA using Moloney murine leukemia virus reverse transcriptase (Promega Corporation, Madison, WI, USA). The reaction system for reverse transcription consisted of $4 \mu \mathrm{l} 5 \mathrm{X}$ RT buffer, $0.75 \mu \mathrm{l}$ dNTP (10 mM), $1.2 \mu 1$ primer (Guangzhou RiboBio Co., Ltd., Guangzhou, China), 0.2 $\mu 1$ MMLV Reverse Transcriptase, $3 \mu \mathrm{g}$ RNA and double distilled water. The thermocycling conditions for reverse transcription were as follows: $25^{\circ} \mathrm{C}$ for $30 \mathrm{~min} ; 42^{\circ} \mathrm{C}$ for $30 \mathrm{~min}$; and $85^{\circ} \mathrm{C}$ for $5 \mathrm{~min}$. The expression levels of miR-216b and SOX9 mRNA were measured using SYBR Premix Ex Taq ${ }^{\mathrm{TM}}$ (Takara Biotechnology Co., Ltd., Dalian, China) in Applied Biosystems Real time PCR System (Applied Biosystems; Thermo Fisher Scientific, Inc.). The $20 \mu 1$ reaction system for qPCR consisted of $10 \mu \mathrm{l}$ SYBR-Green I mix, $2 \mu 1$ forward primer, $2 \mu l$ reverse primer, $2 \mu \mathrm{l}$ cDNA and $4 \mu \mathrm{l}$ double distilled water. The thermocycling conditions for qRCR were as follows: $95^{\circ} \mathrm{C}$ for $30 \mathrm{sec} ; 40$ cycles of $95^{\circ} \mathrm{C}$ for $5 \mathrm{sec}$; and $60^{\circ} \mathrm{C}$ for $30 \mathrm{sec}$. The primer sequences used were as follows: miR-216b forward, 5'-GCCGCGCTAAAGTGC TTATAGTG-3' and reverse, 5'-CACCAGGGTCCGAGGT-3'; U6 forward, 5'-TGCGGGTGCTCGCTTCGGCAGC-3' and reverse, 5'-CCAGTGCAGGGTCCGAGGT-3'; SOX9 forward, 5'-AGGTGCTCAAAGGCTACGACTG-3' and reverse, 5'-CCTAATGTTCATGGTCGGCGC-3'; and GAPDH forward, 5'-TGTGGGCATCAATGGATTTGG -3' and reverse, 5'-ACACCATGTATTCCGGGTCAAT-3'. miR-216b expression was normalized to U6, and GADPH was an internal control for SOX9 mRNA expression. RT-qPCR results were calculated using the $2^{-\Delta \Delta \mathrm{Cq}}$ method (23). Each sample was analyzed in triplicate.

Cell proliferation assay. Cell proliferation was assayed using the Cell Counting Kit-8 (CCK8; Dojindo Molecular Technologies, Inc., Kumamoto, Japan). The NSCLC cells were seeded into the 96-well plates with 3,000 cells/well. Subsequent to incubation at $37^{\circ} \mathrm{C}$ for $6-8 \mathrm{~h}$, the cells were transfected with miRNA or siRNA. Cell proliferation assays were performed for $24 \mathrm{~h}$ until $96 \mathrm{~h}$ post-transfection, whereby $10 \mu 1$ CCK8 solution was added into each well. The 96-well plates were incubated at $37^{\circ} \mathrm{C}$ for $4 \mathrm{~h}$ and the absorbance at $450 \mathrm{~nm}$ was detected with a microplate reader.

Cell invasion assay. A cell invasion assay was performed using Transwell plates (8-mm pores; BD Biosciences, San Jose, CA, USA) coated with Matrigel (BD Biosciences). Cells transfected with miRNA or siRNA were re-suspended and seeded in the upper chambers at a density of $1 \times 10^{5}$ cells in $200 \mu \mathrm{l}$ FBS-free medium. The lower portion of the chamber was filled with $500 \mu \mathrm{l}$ culture medium containing 20\% FBS as a chemoattractant. Subsequent to $24 \mathrm{~h}$ incubation at $37^{\circ} \mathrm{C}$, the non-invaded cells were removed using a cotton swab, and the invading cells were stained with methanol and $0.1 \%$ crystal violet, and counted under an inverted microscope (IX71; Olympus Corp., Tokyo, Japan).

Western blotting analysis. A total of $48 \mathrm{~h}$ subsequent to transfection, the cells were harvested and lysed using radioimmunoprecipitation assay buffer (Beyotime Institute of Biotechnology, Haimen, China) supplemented with a protease inhibitor cocktail (Roche Diagnostics, Basel, Switzerland). The concentration of the total protein was determined with Pierce bicinchoninic acid Protein Assay kit (Thermo Fisher Scientific, Inc.). A total of $20 \mu \mathrm{g}$ protein was separated by $10 \%$ SDS-PAGE, and the separated proteins were transferred to polyvinylidene fluoride (Bio-Rad Laboratories, Hercules, CA, USA) membranes. The membranes were then blocked for $1 \mathrm{~h}$ with $5 \%$ non-fat milk in TBS containing $0.05 \%$ Tween-20 (TBST) at room temperature, followed by incubation at $4^{\circ} \mathrm{C}$ overnight with primary antibodies. Mouse anti-human monoclonal antibodies directed against SOX9 (cat. no. 166505; 1:1,000 dilution) and GADPH (cat. no. 166574; 1:1,000 dilution; both Santa Cruz Biotechnology, Inc.) were used. The membranes were washed with TBST three times, probed with the corresponding horseradish peroxidase-conjugated secondary antibody (dilution, 1:5,000; cat. no. sc-2005; Santa Cruz Biotechnology, Inc.) for $1 \mathrm{~h}$ at room temperature and visualized using Pierceä ECL Western Blotting Substrate (Thermo Fisher Scientific, Inc.). In the present study, GADPH was used as an endogenous control to normalize the expression level of SOX9. 
Target gene predication and luciferase report assay. To validate the direct target gene of miR-216b, an online bioinformatics search using TargetScan (24) was performed. Luciferase reporter vectors pGL3-SOX9-3'UTR wild-type (Wt) and pGL3-SOX9-3'UTR mutant (Mut) were synthesized by Shanghai GenePharma Co., Ltd. The HEK293T cells were transfected with Luciferase reporter vectors and miR-216b mimics or NC using Lipofectamine ${ }^{\circledR} 2000$. At 48 h subsequent to incubation, luciferase activities were determined using Dual Luciferase Reporter Assay kit (Promega Corporation), following the protocol of the manufacturer.

Statistical analysis. Data was presented as the mean \pm standard deviation based on a minimum of 3 separate experiments. SPSS (version 13.0; SPSS Inc., Chicago, IL, USA) was used for statistical analysis. $\mathrm{P}<0.05$ was considered to indicate a statistically significant difference.

\section{Results}

Expression levels of miR-216b in NSCLC tissues and cell lines. To understand the association between miR-216b and NSCLC, miR-216b expression levels in NSCLC tissues and the adjacent non-tumor lung tissues were measured by qPCR. The results demonstrate that $14 / 16$ of NSCLC tissues exhibited lower miR-216b expression compared with adjacent non-tumor lung tissues, as illustrated in Fig. 1A. The miR-216b expression levels were also measured in four human NSCLC cell lines including H23, H460, H520 and A549. The results revealed that miR-216 was downregulated in all four human NSCLC cell lines compared with those in normal bronchial epithelial $16 \mathrm{HBE}$ cell line (Fig. 1B). These results indicate that miR-216b may serve an important role in NSCLC.

miR-216b inhibited NSCLC cell proliferation. To investigate the role of miR-216b in NSCLC cells, the effect of miR-216b on NSCLC cell proliferation was examined. miR-216b mimics or $\mathrm{NC}$ were introduced into the $\mathrm{H} 23$ and A549 cells, which exhibit a low expression of miR-216b. Subsequent to transfection, miR-216b was significantly upregulated in the H23 and A549 cells, as demonstrated in Fig. 2A. Cell proliferation assays were performed to evaluate the effect of miR-216b on NSCLC cell proliferation. The results demonstrate that miR-216b overexpression decreased the level of cell proliferation in the H23 and A549 cells, as illustrated in Fig. 2B.

miR-216b inhibited NSCLC cell invasion. Invasion capacity is essential for cancer cell metastasis. Therefore, the effect of miR-216b on the invasion capacity of NSCLC cells was evaluated. The invasion assay revealed that cell invasion capacity was markedly reduced in the miR-216b mimic-treated $\mathrm{H} 23$ and A549 cells compared with the NC groups, as illustrated in Fig. 3. These findings indicate that miR-216b was downregulated in NSCLC, and acted as a tumor suppressor in NSCLC proliferation and invasion.

SOX9 was the target of miR-216b in NSCLC. To investigate the molecular mechanisms of the suppressive roles of miR-216b on NSCLC cell proliferation and invasion, an online bioinformatics analysis was performed using TargetScan.
The analysis demonstrated that SOX9 was the direct target of miR-216b, as illustrated in Fig. 4A. A luciferase report assay was then performed to examine if miR-216b may directly target SOX9. The results revealed that the level of luciferase activity was significantly reduced in the miR-216b mimics and pGL3-SOX9-3'UTR Wt transfected HEK293T cells. Additionally, the suppressive effect of miR-216b was inhibited by pGL3-SOX9-3'UTR Mut, as illustrated in Fig. 4B.

The expression levels of SOX9 subsequent to transfection with miR-216b mimics or NC were determined. The results demonstrate that miR-216b overexpression led to a decrease in SOX9 mRNA and protein levels, illustrated in Fig. 4C and D, respectively, in the $\mathrm{H} 23$ and A549 cells. Based on these data, the present study suggests that SOX9 was the target of miR-216b in NSCLC.

SOX9 downregulation was the mechanism of miR-216b inhibiting the proliferation and invasion of NSCLC cells. To determine if miR-216b inhibits the proliferation and invasion of NSCLC cells by targeting SOX9, RNA interference was used to decrease the level of SOX9 in the H23 and A549 cells. The SOX9 protein expression levels were measured by western blot analysis, as illustrated in Fig. 5A. The cell proliferation assay revealed that the levels of cell proliferation were suppressed in SOX9-siRNA transfected H23 and A549 cells compared with siRNA-NC groups, as demonstrated in Fig. 5B. The cell invasion assay revealed that the cell invasion ability was also decreased subsequent to transfection with SOX9 siRNA, as illustrated in Fig. 5C. These data indicate that SOX9 downregulation was the mechanism of the miR-216b-inhibited proliferation and invasion of NSCLC cells.

\section{Discussion}

Previous studies have demonstrated that miRNAs are frequently deregulated in NSCLC, and certain miRNAs are associated with particular clinicopathological features of patients with NSCLC, such as metastasis, recurrence and prognosis (25-27). In addition, miRNAs have been revealed to act as tumor suppressors or oncogenes in the carcinogenesis and progression of NSCLC, and have been revealed to be involved in numerous aspects of cancer biology, including cell proliferation, the cell cycle, apoptosis, migration and invasion $(28,29)$. Therefore, the identification of the cancer-specific miRNAs and corresponding direct target genes that are essential for NSCLC carcinogenesis and progression may provide promising therapeutic targets for patients with NSCLC.

In the present study, the expression and functions of miR-216b in NSCLC were investigated, and it was revealed that miR-216b was significantly downregulated in NSCLC tissues and cell lines compared with adjacent non-tumor lung tissue and normal bronchial epithelial cells, respectively. miR-216b overexpression inhibited NSCLC cell proliferation and invasion. Additionally, bioinformatics analysis demonstrated that SOX9 was a target gene of miR-216b. The luciferase report assays revealed that miR-216b was able to bind to SOX93'UTR and decrease the level of SOX9 mRNA and protein expression in NSCLC. These results suggest that miR-216b/SOX9 interactions may be evaluated as a novel strategy in the future 

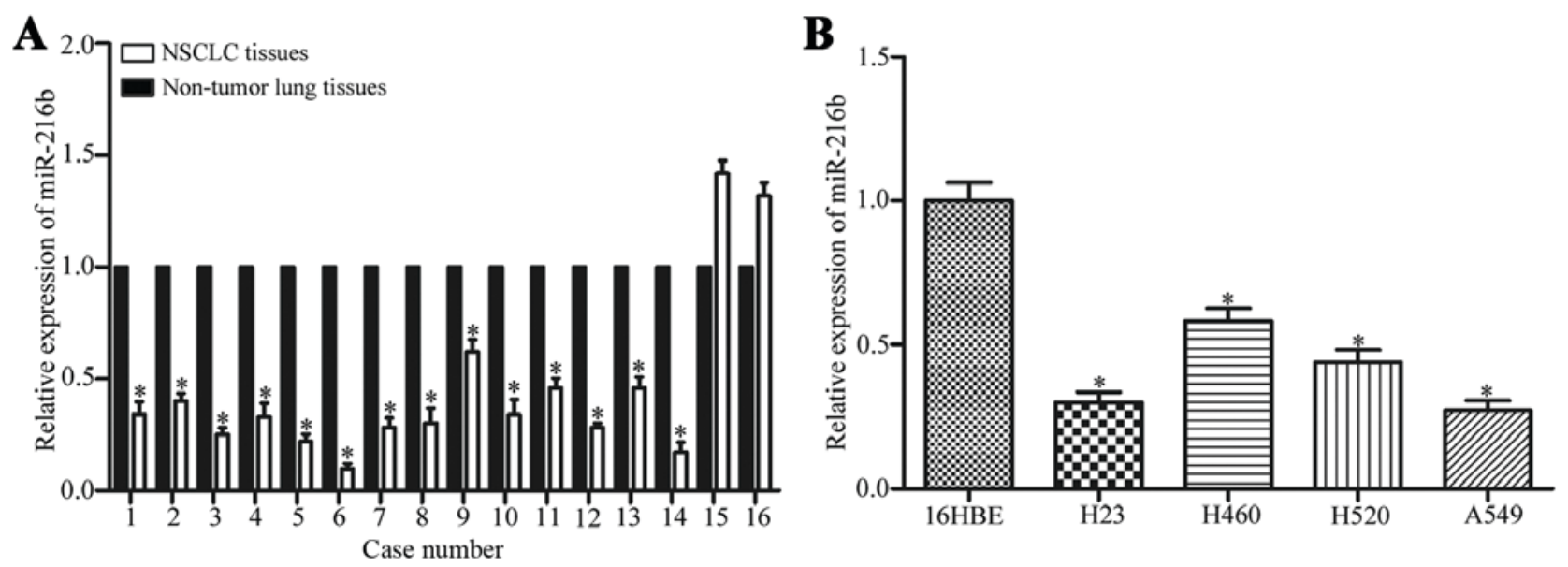

Figure 1. Expression levels of miR-216b were downregulated in NSCLC tissues and cell lines. (A) miR-216b was significantly downregulated in NSCLC tissues compared with the adjacent non-tumor lung tissues. (B) Quantitative analysis of the miR-216b by qPCR in four NSCLC cell lines. Data is presented as the mean \pm standard deviation. Experiments were performed in triplicate and repeated three times. "P $<0.05$. miR, microRNA; NSCLC, non-small cell lung cancer.
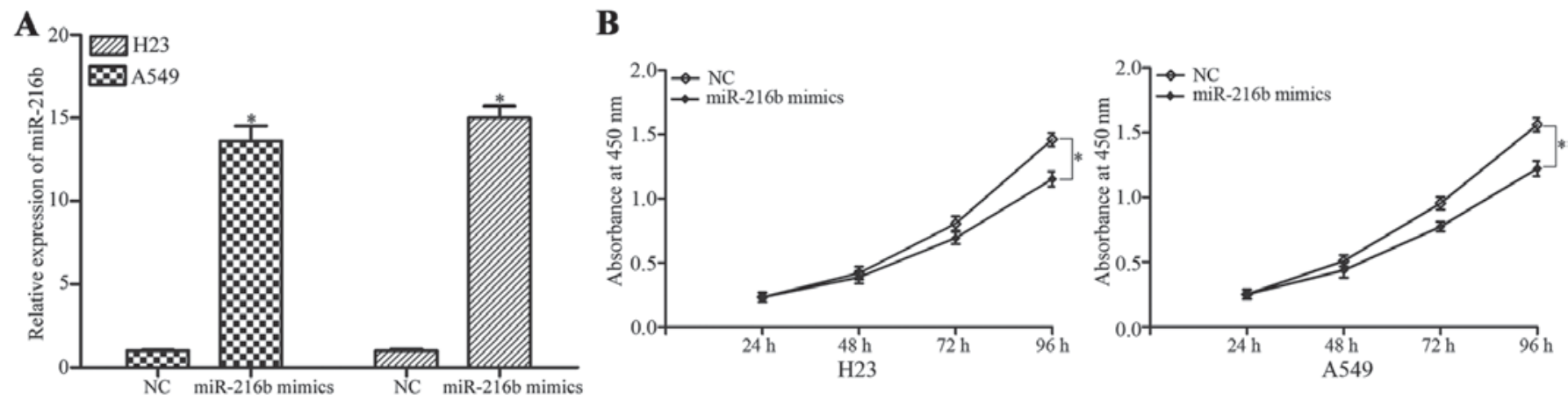

Figure 2. miR-216b inhibited NSCLC cell proliferation. (A) H23 and A549 cells were transfected with miR-216b mimics or NC. Reverse transcription quantitative polymerase chain reaction was adopted to determine the miR-216b expression subsequent to transfection. (B) Effect of miR-216b overexpression on the proliferation of $\mathrm{H} 23$ and $\mathrm{A} 549$ cells was assessed using cell proliferation assay. ${ }^{*} \mathrm{P}<0.05$. miR, microRNA; $\mathrm{NC}$, negative control.

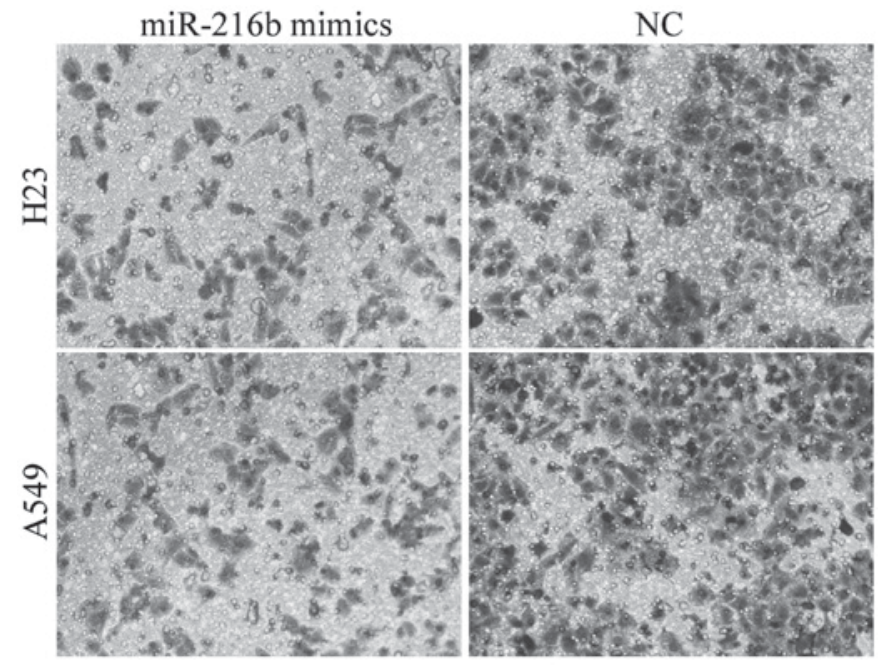

Figure 3. Effect of miR-216b overexpression on the invasion capacity of $\mathrm{H} 23$ and A549 cells was evaluated using cell invasion assay. Upregulation of miR-216b expression decreased the invasion capacity of $\mathrm{H} 23$ and A549 cells ${ }^{*} \mathrm{P}<0.05$. miR, microRNA; NC, negative control.

with respect to control of the rapid growth and metastasis of NSCLC.
miR-216b, a member of the miR-216 family, is located at chromosome 2p16.1 and has been reported to be associated with a number of types of human cancer (30). miR-216b expression was reduced in gastric adenocarcinoma, and was demonstrated to inhibit proliferation and cell cycle progression by directly targeting histone deacetylase 8 (31). In another study, miR-216b was significantly downregulated in hepatocellular carcinoma and the low expression levels were correlated with tumor volume, hepatitis B virus (HBV) infection, HBV DNA quantity and vascular invasion. The restoration of miR-216b expression suppressed the proliferation, migration and invasion of hepatocellular carcinoma cells through the negative regulation of insulin like growth factor 2 mRNA binding protein 2 (32). In addition, miR-216b was demonstrated to be underexpressed in breast cancer. The ectopic expression of miR-216 targeted purinergic receptor P2X 7 and decreased the level of growth of breast cancer cells (33). Additional studies revealed that nasopharyngeal carcinoma cells exhibited lower miR-216b expression and inhibited proliferation, migration and invasion by targeting V-Ki-ras2 Kirsten rate sarcoma viral oncogene and protein kinase $\mathrm{C} \alpha(34,35)$.

Also, in the present study the molecular mechanism of miR-216b-inhibited proliferation and invasion of NSCLC cells was investigated. Online bioinformatics analysis demonstrated that SOX9 was a potential target gene of miR-216b. In order 
$\mathbf{A}$

'SOX93' UTR Wt

hsa-miR-216b

SOX9 3' UTR Mut
5' ...UUUUUUGUAUAAaUgagagauUG...

3. AGUGUAAACGGACGUCUCUAAA

5' ...UUUUUUGUAUAAAUGUCUCUAAG..
B

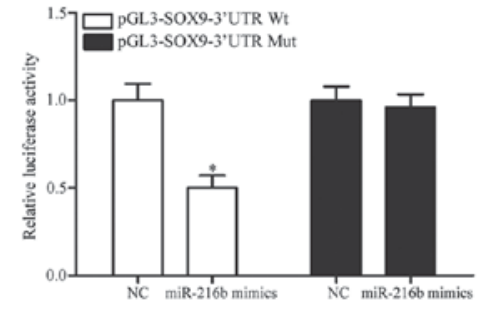

D

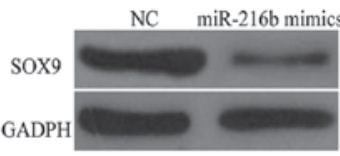

$\mathrm{H} 23$

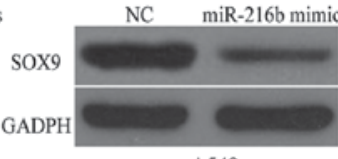

A549

Figure 4. miR-216b directly targeted SOX9 and decreased its expression. (A) Predicted miR-216b binding sequence in the SOX9 3'UTR. The corresponding mutant counterpart was generated in the SOX9 3'UTR sequence in the complementary site for the seed region of miR-216b. (B) The pGL3-SOX9-3'UTR Wt or pGL3-SOX9-3'UTR Mut luciferase reporter vector was co-transfected into HEK293T cells with miR-216b mimics or NC. (C) SOX9 expression at mRNA level measured using qPCR. (D) SOX9 expression at protein levels subsequent to transfection with miR-216b mimics or NC measured using western blot analysis. ${ }^{*} \mathrm{P}<0.05$. has-miR, human microRNA; NC, negative control; SOX9, sex determining region Y-Box 9; UTR, untranslated region; wt, wild type; Mut, mutant.

$\mathbf{A}$

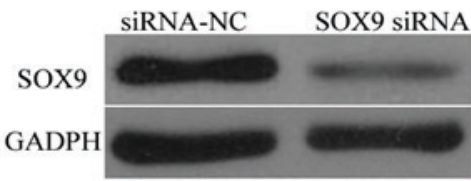

$\mathrm{H} 23$

\section{B}

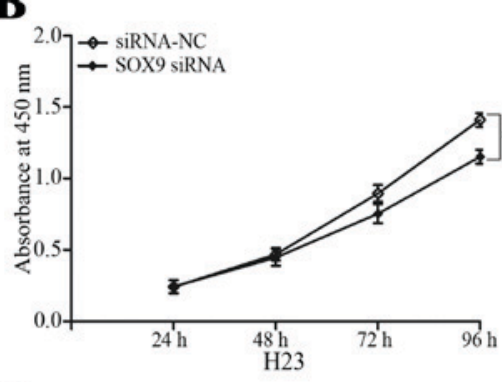

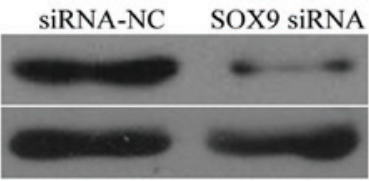

A549

$\mathbf{C}$

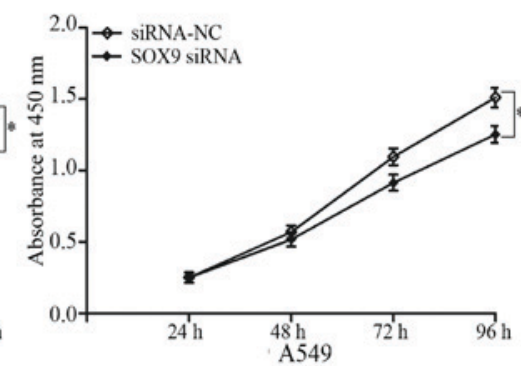

SOX9 SiRNA

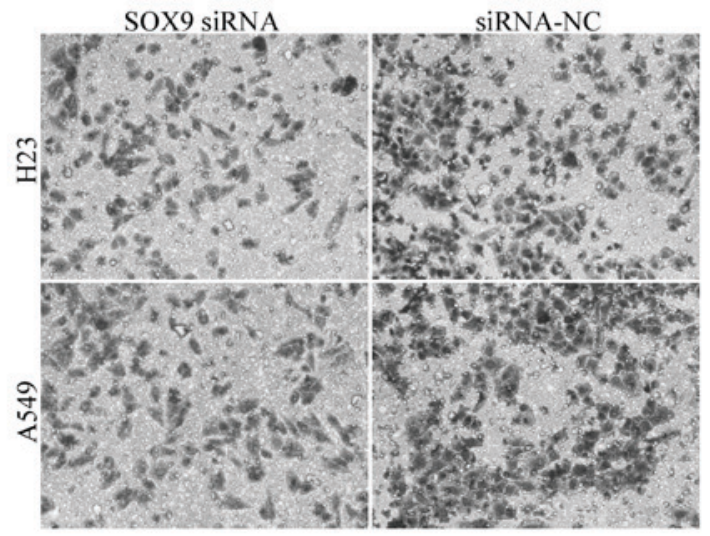

Figure 5. SOX9 downregulation was the mechanism of miR-216b inhibiting the proliferation and invasion of NSCLC cells. (A) H23 and A549 cells were transfected with SOX9 siRNA or siRNA-NC. Western blot analysis was used to measure the SOX9 expression subsequent to transfection. (B) Effect of SOX9 downregulation on the proliferation of $\mathrm{H} 23$ and A549 cells was assessed using a cell proliferation assay. (C) Effect of SOX9 downregulation on the invasion capacity of $\mathrm{H} 23$ and A549 cells was evaluated using a cell invasion assay. ${ }^{*} \mathrm{P}<0.05$. SOX9, sex determining region Y-Box 9; siRNA, small interfering RNA; $\mathrm{NC}$, negative control.

to test whether miR-216b directly participates in the regulation of SOX9 gene expression, luciferase report assays were performed. By measuring changes in the luciferase activity, the regulation of SOX9 by miR-216b was demonstrated. In addition, RT-qPCR and western blot analysis revealed that SOX9 expression at the mRNA and protein levels were 
downregulated by miR-216b overexpression. In addition, SOX9 knockdown may mimic miR-216b-induced proliferation and invasion of NSCLC cells. These results demonstrate that miRNA-216b inhibited the proliferation and invasion of NSCLC cells through negatively regulating the expression of SOX9 by directly targeting the 3 'UTR.

SOX9 has been reported to be highly expressed in a number of types of human cancer, such as prostate (36), breast (37) and colorectal (38) cancer. In NSCLC, SOX9 was upregulated at mRNA and protein levels, and the expression levels were associated with the histological stage of NSCLC and patients with a high SOX9 level exhibited a shorter survival rate. Multivariate analysis illustrated that SOX9 upregulation may be an independent prognostic indicator for the survival of patients with NSCLC (39). The overexpression of SOX9 may enhance proliferation, migration and invasion of lung adenocarcinoma cells (40). These data suggest that SOX9 was a suitable target for patients with NSCLC.

Several studies revealed that SOX9 functions as an oncogene and is regulated by multiple miRNAs in various types of human cancer. In chondrosarcoma, Li et al (41) revealed that miR-494 suppressed cell proliferation and invasion in vitro and in vivo by directly targeting SOX9. In glioma, head and neck cancer, miR-145 acted as a tumor suppressor through the negative regulation of SOX9 $(42,43)$. Also in NSCLC, miR-206 (44) and miR-32 (45) targeted SOX9 to function in tumor suppressive roles. SOX9 was also targeted by miRNAs in other types of human cancer, including miR-32 in osteosarcoma (46), miR-140 in breast cancer (47) and miR-101 in hepatocellular carcinoma (48). In the present study, miR-216b was demonstrated to inhibit the proliferation and invasion of NSCLC cells by negatively regulating the expression of SOX 9 via directly targeting the $3^{\prime} \mathrm{UTR}$. Therefore, miR-216b may be used as a therapeutic target to prevent rapid growth and metastasis in NSCLC.

In conclusion, the present study provided initial data that miR-216b is downregulated and inhibits the cellular proliferation and invasion of NSCLC through the direct targeting of SOX9. The association between miRNA-216b expression and NSCLC progression indicates that miR-216b/SOX9 may be potential therapeutic targets for patients with NSCLC.

\section{References}

1. Jemal A, Siegel R, Xu J and Ward E: Cancer statistics, 2010. CA Cancer J Clin 60: 277-300, 2010.

2. Siegel RL, Miller KD and Jemal A: Cancer statistics, 2015. CA Cancer J Clin 65: 5-29, 2015

3. Robinson KW and Sandler AB: The role of MET receptor tyrosine kinase in non-small cell lung cancer and clinical development of targeted anti-MET agents. Oncologist 18: 115-122, 2013.

4. Spira A and Ettinger DS: Multidisciplinary management of lung cancer. N Engl J Med 350: 379-392, 2004.

5. Wu Q, Chen YF, Fu J, You QH, Wang SM, Huang X, Feng XJ and Zhang SH: Short hairpin RNA-mediated down-regulation of CENP-A attenuates the aggressive phenotype of lung adenocarcinoma cells. Cell Oncol (Dordr) 37: 399-407, 2014.

6. De Marinis F, Bria E, Baas P, Tiseo M, Camerini A, Favaretto AG and Gridelli C: Treatment of unfit patients with advanced non-small-cell lung cancer: Definition criteria according an expert panel. Clin Lung Cancer 16: 399-405, 2015.

7. Bichev SN, Marinova DM, Slavova YG and Savov AS: Epidermal growth factor receptor mutations in East European non-small cell lung cancer patients. Cell Oncol (Dordr) 38: $145-153,2015$.
8. Zhong C, Ding S, Xu Y and Huang H: MicroRNA-222 promotes human non-small cell lung cancer H460 growth by targeting p27. Int J Clin Exp Med 8: 5534-5540, 2015.

9. Shukla GC, Singh J and Barik S: MicroRNAs: Processing, maturation, target recognition and regulatory functions. Mol Cell Pharmacol 3: 83-92, 2011.

10. Ambros V: The functions of animal microRNAs. Nature 431: 350-355, 2004.

11. Lewis BP, Burge CB and Bartel DP: Conserved seed pairing, often flanked by adenosines, indicates that thousands of human genes are microRNA targets. Cell 120: 15-20, 2005.

12. Donadeu FX, Schauer SN and Sontakke SD: Involvement of miRNAs in ovarian follicular and luteal development. J Endocrinol 215: 323-334, 2012.

13. Liwak U, Faye MD and Holcik M: Translation control in apoptosis. Exp Oncol 34: 218-230, 2012.

14. Rutnam ZJ and Yang BB: The involvement of microRNAs in malignant transformation. Histol Histopathol 27: 1263-1270, 2012.

15. Zhang B, Pan X, Cobb GP and Anderson TA: microRNAs as oncogenes and tumor suppressors. Dev Biol 302: 1-12, 2007.

16. Chen L, Zhang F, Sheng XG, Zhang SQ, Chen YT and Liu BW: MicroRNA-106a regulates phosphatase and tensin homologue expression and promotes the proliferation and invasion of ovarian cancer cells. Oncol Rep 36: 2135-2141, 2016.

17. Zeng Y, Fu M, Wu GW, Zhang AZ, Chen JP, Lin HY, Fu YA, Jia J, Cai ZD, Wu XJ and Lan P: Upregulation of microRNA-370 promotes cell apoptosis and inhibits proliferation by targeting PTEN in human gastric cancer. Int J Oncol 49: 1589-1599, 2016.

18. Lanford RE, Hildebrandt-Eriksen ES, Petri A, Persson R, Lindow M, Munk ME, Kauppinen S and Ørum H: Therapeutic silencing of microRNA-122 in primates with chronic hepatitis C virus infection. Science 327: 198-201, 2010.

19. Trang P, Medina PP, Wiggins JF, Ruffino L, Kelnar K, Omotola M, Homer R, Brown D, Bader AG, Weidhaas JB and Slack FJ: Regression of murine lung tumors by the let-7 microRNA. Oncogene 29: 1580-1587, 2010.

20. Johnson SM, Grosshans H, Shingara J, Byrom M, Jarvis R, Cheng A, Labourier E, Reinert KL, Brown D and Slack FJ: RAS is regulated by the let-7 microRNA family. Cell 120: 635-647, 2005.

21. van Rooij E, Sutherland LB, Qi X, Richardson JA, Hill J and Olson EN: Control of stress-dependent cardiac growth and gene expression by a microRNA. Science 316: 575-579, 2007.

22. Montgomery RL, Hullinger TG, Semus HM, Dickinson BA, Seto AG, Lynch JM, Stack C, Latimer PA, Olson EN and van Rooij E: Therapeutic inhibition of miR-208a improves cardiac function and survival during heart failure. Circulation 124: 1537-1547, 2011.

23. Livak KJ and Schmittgen TD: Analysis of relative gene expression data using real-time quantitative PCR and the 2(-Delta Delta C(T)) Method. Methods 25: 402-408, 2001.

24. Agarwal V, Bell GW, Nam JW and Bartel DP: Predicting effective microRNA target sites in mammalian mRNAs. Elife 4: e05005, 2015 .

25. Cortinovis D, Monica V, Pietrantonio F, Ceresoli GL, La Spina CM and Wannesson L: MicroRNAs in non-small cell lung cancer: Current status and future therapeutic promises. Curr Pharm Des 20: 3982-3990, 2014

26. Vannini I, Fanini F and Fabbri M: MicroRNAs as lung cancer biomarkers and key players in lung carcinogenesis. Clin Biochem 46: 918-925, 2013.

27. Boeri M, Pastorino U and Sozzi G: Role of microRNAs in lung cancer: microRNA signatures in cancer prognosis. Cancer J 18: 268-274, 2012.

28. Lei L, Huang Y and Gong W: miR-205 promotes the growth, metastasis and chemoresistance of NSCLC cells by targeting PTEN. Oncol Rep 30: 2897-2902, 2013.

29. Yuan Y, Shen Y, Xue L and Fan H: miR-140 suppresses tumor growth and metastasis of non-small cell lung cancer by targeting insulin-like growth factor 1 receptor. PLoS One 8: e73604, 2013.

30. Shao JY, Huang XM, Yu XJ, Huang LX, Wu QL, Xia JC, Wang HY, Feng QS, Ren ZF, Ernberg I, et al: Loss of heterozygosity and its correlation with clinical outcome and Epstein-Barr virus infection in nasopharyngeal carcinoma. Anticancer Res 21: 3021-3029, 2001.

31. Wang Y, Xu P, Yao J, Yang R, Shi Z, Zhu X, Feng X and Gao S: MicroRNA-216b is down-regulated in human gastric adenocarcinoma and inhibits proliferation and cell cycle progression by targeting oncogene HDAC8. Target Oncol 11: 197-207, 2016. 
32. Liu FY, Zhou SJ, Deng YL, Zhang ZY, Zhang EL, Wu ZB, Huang ZY and Chen XP: MiR-216b is involved in pathogenesis and progression of hepatocellular carcinoma through HBx-miR-216b-IGF2BP2 signaling pathway. Cell Death Dis 6: e1670, 2015.

33. Zheng L, Zhang X, Yang F, Zhu J, Zhou P, Yu F, Hou L, Xiao L, He Q and Wang B: Regulation of the P2X7R by microRNA-216b in human breast cancer. Biochem Biophys Res Commun 452: 197-204, 2014

34. Deng M, Tang H, Zhou Y, Zhou M, Xiong W, Zheng Y, Ye Q, Zeng X, Liao Q, Guo X, et al: miR-216b suppresses tumor growth and invasion by targeting KRAS in nasopharyngeal carcinoma. J Cell Sci 124: 2997-3005, 2011

35. Deng M, Liu JF, Gu YX, Zheng GP and He ZM: miR-216b suppresses cell proliferation and invasion by targeting $\mathrm{PKCa}$ in nasopharyngeal carcinoma cells. Zhonghua Zhong Liu Za Zhi 35: 645-650, 2013 (In Chinese).

36. Wang H, Leav I, Ibaragi S, Wegner M, Hu GF, Lu ML, Balk SP and Yuan X: SOX9 is expressed in human fetal prostate epithelium and enhances prostate cancer invasion. Cancer Res 68 : 1625-1630, 2008.

37. Muller P, Crofts JD, Newman BS, Bridgewater LC, Lin CY, Gustafsson JA and Ström A: SOX9 mediates the retinoic acid-induced HES-1 gene expression in human breast cancer cells. Breast Cancer Res Treat 120: 317-326, 2010.

38. Bruun J, Kolberg M, Nesland JM, Svindland A, Nesbakken A and Lothe RA: Prognostic significance of $\beta$-Catenin, E-Cadherin and SOX9 in colorectal cancer: Results from a Large population-representative series. Front Oncol 4: 118, 2014.

39. Zhou CH, Ye LP, Ye SX, Li Y, Zhang XY, Xu XY and Gong LY: Clinical significance of SOX9 in human non-small cell lung cancer progression and overall patient survival. J Exp Clin Cancer Res 31: 18, 2012.
40. Wang X, Ju Y, Zhou MI, Liu X and Zhou C: Upregulation of SOX9 promotes cell proliferation, migration and invasion in lung adenocarcinoma. Oncol Lett 10: 990-994, 2015.

41. Li J, Wang L, Liu Z, Zu C, Xing F, Yang P, Yang Y, Dang X and Wang K: MicroRNA-494 inhibits cell proliferation and invasion of chondrosarcoma cells in vivo and in vitro by directly targeting SOX9. Oncotarget 6: 26216-26229, 2015.

42. Rani SB, Rathod SS, Karthik S, Kaur N, Muzumdar D and Shiras AS: MiR-145 functions as a tumor-suppressive RNA by targeting Sox 9 and adducin 3 in human glioma cells. Neuro Oncol 15: 1302-1316, 2013.

43. Yu CC, Tsai LL, Wang ML, Yu CH, Lo WL, Chang YC, Chiou GY, Chou MY and Chiou SH: miR145 targets the SOX9/ADAM17 axis to inhibit tumor-initiating cells and IL-6-mediated paracrine effects in head and neck cancer. Cancer Res 73: 3425-3440, 2013.

44. Zhang YJ, Xu F, Zhang YJ, Li HB, Han JC and Li L: miR-206 inhibits non small cell lung cancer cell proliferation and invasion by targeting SOX9. Int J Clin Exp Med 8: 9107-9113, 2015.

45. Zhu D, Chen H, Yang X, Chen W, Wang L, Xu J and Yu L: miR-32 functions as a tumor suppressor and directly targets SOX9 in human non-small cell lung cancer. Onco Targets Ther 8: 1773-1783, 2015

46. Xu JQ, Zhang WB, Wan R and Yang YQ: MicroRNA-32 inhibits osteosarcoma cell proliferation and invasion by targeting Sox 9 . Tumour Biol 35: 9847-9853, 2014.

47. Li Q, Yao Y,Eades G,Liu Z,Zhang Y and Zhou Q: Downregulation of miR-140 promotes cancer stem cell formation in basal-like early stage breast cancer. Oncogene 33: 2589-2600, 2014.

48. Zhang Y, Guo X, Xiong L, Kong X, Xu Y, Liu C, Zou L, Li Z, Zhao J and Lin N: MicroRNA-101 suppresses SOX9-dependent tumorigenicity and promotes favorable prognosis of human hepatocellular carcinoma. FEBS Lett 586: 4362-4370, 2012. 